\title{
Un caso de prescripción en la acción de alimentos
}

\section{por ANTONIO VALDEZ CALLE}

Es materia de este trabajo la prescripción de la acción de alimentos que, en favor del hijo ilegtimo no reconocido, concede el art. 367 del codigo civil.

El art. 366 del código indicado señala en cinco incisos los casos en que la paternidad, a falta de voluntaria manifestación, puede ser judicialmente declarada. Como es natural, el art. 366 no contempla todos los casos en que un hombre puede ser padre, pero si vé las situaciones en que sin lugar a duda hay certeza de la paternidad.

Pero cabe la posibilidad de que un hombre sea padre por el mero hecho de haber sostenido ocasionales relaciones sexuales con la madre del nuevo ser. El legislador para no dejar en completo desamparo al posible fruto de esas relaciones -que por su misma naturaleza de presumible, más no de cierto, no puede estar en la misma situación que el fruto de uniones legítimas o de uniones ilegítimas pero estables como el concubinato- lo ha concedido la acción del art. 367, que constituye un avance de carácter social en el campo de las legislaciones positivas, al establecer la obligación de prestar alimentos que tiene quien sostuvo relaciones con la madre del hijo durante la época de su concepción.

La acción del art. 367 se encuentra encuadrada, entre otros, por el art. 382, que señala un plazo de tres años para ejercitarla y el que comenzará a contarse desde el día del nacimiento, o desde la cesación de los socorros suministrados directa o indirectamente por el demandado.

Pero en la práctica, la aplicación del art. 382 encuentra según el sentir de muchas ejecutorias supremas (1), la valla del art. 454, que dice: "El derecho de pedir alimentos es intrasmisible y no puede ser objeto de renuncia, de transacción, ni de compensación"; o sea que de acuerdo a la letra de los dos dispositivos señalados, hay manifiesta contradicción, en este aspecto, dentro del régimen de los alimentos.

Un examen detenido de los artículos aparentemente contradictorios nos hará ver que la pretendida colisión entre sus mandatos no es real, ya que uno, el 454 , legisla los alimentos en general, mientras otro, el 382 , es regla, únicamente, para un caso especial contemplado por el legislador. y que por lo tanto es lógico sea legislado con disposiciones también de carácter especial.

El art. 441 precisa a quienes alcanzan los alimentos, y señala a los conyuges, a los ascendientes y descendientes y a los hermanos. EI inc. $2^{\circ}$. 
de este articulo podría ser aplicado favorablemerte a la tesis contraria a la aplicación del art. 382, diciéndose que si la ley no hace distingos entre la calidad de los descendientes a que se refiere el inciso en cuestión. nadie puede arrogarse la facultad de ponerle limitaciones que puedan perjudicar legítimos derechos.

Pero la doctrina y las legislaciones, casi en general, consideran que el derecho de pedir alimentos que corresponde a los hijos "se halla subordunado al establecimiento de la filiación por las formas de prueba admitidas por la ley" (Planiol y Ripert). Por otro lado, en el tratado de Derecho Civil de Colin y Capitant se lee: "Ya hemos dicho que para que el hijo natural tenga derecho a alimentos y educación necesita poder invocar una filiación legalmente establecida, la cual puede resultar, ya de un reconocimiento voluntario, ya de una sentencia, estatuyendo sobre una acción de investigación de la maternidad o de la paternidad. Sin embargo la regla de que el hijo natural' no reconocido no tiene ningún derecho que hacer valer respecto a sus progenitores, no es absoluta...".

De la consideración de los párrafos precedentes así como de otros cuya cita es innecesaria por ser análogos a los conceptos anteriores, se concluye que la reciprocidad del derecho a alimentos que señala el inc. $2^{\circ}$ del art. 441 alcanza solamente a los que tienen claramente establecida su filiación.

La jurisprudencia mundial ha ido atemperando la rigidez de las disposiciones que solo concedían derechos a los hijos cuya filiación estaba probada, al señalar p. ej. que: "Hay una obligación natural a cargo de los padres en relación con el hijo cuya filación no se haya probado legalmente, pues esta obligación naturalmente puede servir a fundamento de una promesa de sostenimiento" (citada por Planiol y Ripert).

Aquello de" no ser absoluta la regla de que el hijo natural no reconocido no tiene ningún derecho que hacer valer respecto a sus progenitores", y por otro lado: "el reconocimiento de una obligación natural que puede servir a fundamento de una promesa de sostenimiento, han sido consagraćos por el legislador peruano en el art. 367, que se halla, no dentro del título que trata de los alimentos, sino del que se ocupa de la filiación ilegítima, para hacer resaltar más su carácter de regla especial. Y como se trata de una institución nueva, insuficientemente experimentada; como a pesar de tener las mismas necesidades los hijos, no se puede imponer las mismas obligaciones al padre cierto y al presunto padre: como el orden jurídico exige que haya plazos para la reclamación de derechos sustentados en hechos cuya certidumbre no está claramente establecida, el código civil del año 1936 ha establecido, junto con otras, la regla del art. 382, que es la única aplicable al caso sui-generis de alimentos, creado por el art. 367.

No hay pues la tal contradicción entre los arts. 454 y 382 . El art. 454 regula los alimentos en su aspecto general, mientras que el art. 382 es regla solo para un caso especial. Ambos legislan algo que en lo genérico es igual, pero que en lo concreto es diferente pues están envueltos dentro de esferas distintas, que por muy parecidas que sean, siempre son diferentes por propio ministerio de la ley, lo cual hace que, a despecho de la amplitud del campo dentro del cual legisla el art. 454, nunca pued irrumpir éste, sin transgredir la ley, en el campo creado por el art. 367 . El mismo código, oor intermedio de los arts. 446 y 477 nos está indicando 
también la existencia de esas dos esferas, al comprender dentro de la alternabilidad de la obligación, solo a los hijos legítimos y a los ilegítimos reconocidos, señalando así, de un modo tácito, que únicamente éstos se encuentran comprendidos dentro del inc. $2^{\circ}$ del art. 441.

$Y$ por muy respetables que sean los sentimientos de humanidad que inspiren la no aplicación del art. 382, el mandato de la ley es claro y terminante: el plazo para interponer la acción es de tres años que comenzarán a contarse desde el día del nacimiento, o desde la cesación de los oocorros suministrados directa o indirectamente por el demandado.

La ley solo puede ser modificada por otra ley; la jurisprudencia por humana y respetable que sea, dentro de un procedimiento estrictamente ajustado a los principios del derecho, no puede modificar nunca a la ley. Puede si señalar tendencias o atemperar rigores cuando las leyes dejan vacíos que son necesariog llenar para la cabal existencia del orden juridico; pero en los casos en que la ley de modo expreso legisla sobre algo, no caben otras reglas que no sean las señaladas, salvo las nuevas, expedidas según los requisitos que les den la fuerza necesaria para sustituir a las anteriores. Y como dice el Dr. Muñóz en un dictamen fiscal publicado en el tomo XXXI de los Anales Judiciales: "Cuando la ley es clara, la interpretación contraria a su texto no puede prevalecer, forque los jueces no pueden modificarla".

\section{(1) DICTAMEN FISCAL}

Señor:

Doña Eduviges Juárez de Ramos ha interpuesto demanda contra don Manuel Sala.. zar, sobre prestación de alimentos para la menor Juana, habida en las relaciones convivenciales con el demandado, quien negó los fundamentos de la demanda y, posteriormente, ha deducidó la prescripción fundada en lo que eatablece el art. 382 del C. Civil.

El Juzgado de Primera Instancia de Arequipa, en la sentencia de $f s$. 48 declaró prescrita la acción de cobro de alimentos; pero la Corte Superior, de conformidad: con el dictamen de su Fiscal de fs. 52 vta., ha revocado la apelada de fa. 66 y declarado sin lugar la prescripción y fundada la demanda. fijando en 40 soles la pensión alimenticia para la menor habida en las convivenciales. Salazar ha interpuesto recurso de nulidad.

El juicio acumulado seguido entre las mismas partes sobre filiación de la indicada menor, terminó desfavorablemente para la demandante, pero ello no es óbice para el ejercicio de la acción de alimentos, desde que se ha probado en autos que Salazar sostuvo relaciones sexuales con la autora durante la época de la concepción de la menor Juana. lo que hace aplicable al caso subjudicó lo que establece el art. 367 del C. Civil.

El art. 382 del miemo Código diepone que el plazo para interponer la acción ea de 3 añoe que comenzarán a contarae deade el día del necimiento, o desde la cesación de los socorro ouministrados directa o indirectamente por el demandado: pero sere diepositivo está en contradicción con el 454 del mismo C6digo que establece que el dérecho de pedir alimentos es intramisible y no puede aer objeto de renuncia, do tranacción ni de compenaución. 
Ya este Tribunal en numerosas ejecutorias, ha establecido la improcedencia de la prescripción en casos análogos, salvaguardando así el derecho de los menores a ser alimentados por sus padres ilegítimos (Revista de la Jurisprudencia Peruana 1945, pág. 606, 1946, pág. 105).

Por las razones expuestas, el Fiscal es de opinión que NO HAY NULIDAD en lo. sentencia recurrida.

Lima, $1^{\circ}$ de maxzo de 1947.

SOTELO

\section{RESOLUCION SUPREMA:}

Lima, quince de abril de mil novecientos cuarentisiete.

Vistos; de conformidad con el dictamen do'. Señor Fiscal: declararon NO HABER NULIDAD en la sentencia de vista de fojas sesentiseis, su fecha catorce de octubre de mil novecientos cuarentiseis, que revocando la de primera instancia de fojas cuarentiocho, su fecha diez de junio del mismo año, declara fundada la demanda interpuesta a foja una por doña Eduviges Juarez de Ramos y fija en cuarenta soles la pensión alimenticia mensual con que don Manuel Salazar debe acudir a la menor Juana; con todo lo demás que dicha sentencia contiene; sin costas; y los devolvieron.- ZAVALA LOAYZA.-- FRISANCHO.- FUENTES ARAGON. - CHECA.-Jorge Vega García. Secretario.

Considerando: que la prueba actuada no acredita la época en que la demandante y el demandado hubieran tenido relaciones sexuales; que la excepción de pres. cripción deducida por el demando a fojas diecinueve por haber transcurrido más de nueve años desde el seis de mayo de mil novecientos treintiseis en que nació la menor Juana, para la que se pide alimentos, hasta la iniciación de la demanda el dieciseis de sgosto de mil novecientos cuarenticinco, es procedente, porque la acción alimenticia ejercida por la demandante, no proviene de una relación jurídica originada por algunos de los casos en que el artículo trescientos sesentisiete del Código Civil, en au primera parte, excluye del término de tres años que para la prescripción extintiva establece el articulo trescientos ochentidós concordante con el trescientos ochentiuno del acotado que derivando esa acçión de relaciones sexuales ocasionales, se encuentra comprendida en la limitación que instituye el precitado artículo trescientos ochentidós, que por ejercitarse a base de presunciones de procreación requiere la ley su ejercicio inmediato para el eficaz esclarecimiento; mi voto es por la nulidad de la sontencia de vista y que reformándola se confirme la de primera instancia que declara prescrita la acción sobre cobro de alimentos interpueata por doña Eduviges Juárez de Ramos.LAINEZ LOZADA. - Se publicó conforme a ley.-Jorge Vega García._- Secretario. 